\title{
Het algemeen-culturele tijdschrift in het negentiende-eeuwse medialandschap
}

\author{
REMIEG AERTS
}

Vijf jaar geleden verscheen het eerste nummer van Ts - Tijdschrift voor tijdschriftstudies, bescheiden gepresenteerd als 'nieuwsbrief' voor tijdschriftonderzoekers, maar door de elegante vormgeving toch direct een echte en zelfs opvallende periodiek. Ik moet bekennen dat dit fenomeen bij mij een ambivalent gevoel opriep. Een contactorgaan als dit moest mij als tijdschriftonderzoeker natuurlijk welkom zijn; het betekende erkenning van een belangrijk interdisciplinair studieveld. Maar ik heb ook, in een goed negentiende-eeuwse traditie van publieksreacties, gedacht: 'Hè, alweer een nieuw tijdschrift?' En eerlijk gezegd beschouwde en beschouw ik Ts •> als een afschrikwekkend voorbeeld van hyperspecialisatie in de wetenschap. Juist nu universiteiten en onderzoeksinstituten van hun leden eisen dat zij bij voorkeur internationaal publiceren, in breed erkende peer reviewed vakbladen, naar het speerpunt- of piramidemodel van de natuur-, medische en sociale wetenschappen, brengt de voortschrijdende specialisatie ons (kunst-)historici en letterkundigen ertoe voor elke subdiscipline eerst een werkgroep en vervolgens een bijbehorend clubblad te stichten. Historici in Nederland beschikken niet alleen over het Tijdschrift voor Geschiedenis, de Bijdragen en Mededelingen betreffende de Geschiedenis der Nederlanden en het Tijdschrift voor Sociale Geschiedenis, maar ook over speciale periodieken voor de interdisciplinaire studie van de klassieke oudheid, de zeventiende eeuw, de achttiende eeuw, de negentiende eeuw en de eigentijdse geschiedenis, universiteitsgebonden historische periodieken, een $\tau$ ijdschrift voor Mediageschiedenis en een Jaarboek voor Nederlandse boekgeschiedenis. Het ontbreekt ons dus bepaald niet aan publicatiemogelijkheden, al of niet streng peer reviewed. Alleen is de vraag met wie wij op deze manier nog een wetenschappelijke communicatiegemeenschap vormen. Het is ieders ervaring tegenwoordig: hoeveel verschillende periodieken moet je niet bijhouden om nog enigszins op de hoogte van je vakgebied te blijven, zelfs als het onderwerp voornamelijk tot Nederland beperkt blijft?

En omdat, zoals bekend, vroeger altijd alles beter was, dwalen de gedach- 
ten terug naar die gulden eenvoud van de negentiende eeuw. Tot voor kort althans leek het toenmalige tijdschriftenlandschap zo overzichtelijk. De negentiende-eeuwers dommelden rustig bij hun Vaderlandsche Letteroefeningen of bladerden wat in Het Leeskabinet, tot zij werden wakker geschud door De Gids, die was voorbereid door De Muzen. In de jaren 1860 kreeg De Gids een lichtvoetiger concurrent in De Nederlandsche Spectator. Toen deze beide bladen zowat hadden uitgediend werden zij in 1885 gelukkig opgevolgd door het artistiek elan van De Nieuwe Gids. Daarna verscheen nog De Kroniek van P.L. Tak als 'brandpunt van Negentig'. Dit was kort samengevat de voorstelling van het negentiende-eeuwse tijdschriftenaanbod tot voor een jaar of vijftien.

Deze selectie - want dat is het - wijkt niet sterk af van de negentiendeeeuwse perceptie. De krant Het Vaderland bevatte bijvoorbeeld in 1875-1876 een rubriek 'Onze tijdschriften'. De periodieken die daarin besproken werden, waren allereerst De Gids (die wel gold als 'zwaar' maar in elk geval als belangrijk) en daarnaast de Vaderlandsche Letteroefeningen (in zijn laatste jaar), De Tijdspiegel, het nieuwe Vragen des Tijds en Eigen Haard, en incidenteel nog wat andere bladen. Een klein aantal vrij serieuze en degelijke periodieken gold in deze liberale Haagse krant dus als vermeldenswaard. ${ }^{1}$

Toch weten we inmiddels beter. Door allerlei bibliografische overzichten, door G.J. Johannes' studie De barometer van de smaak, door de onvolprezen inventarisatie van de geillustreerde publiekstijdschriften door Hemels en Vegt en door oudere en recente studies over wetenschappelijke periodieken, muziektijdschriften en vrouwentijdschriften is het beeld van de negentiende-eeuwse publicistiek veel rijker en diverser geworden. ${ }^{2}$ Het tijdschriftenlandschap was toentertijd al verbazend gevarieerd en gespecialiseerd naar doelgroepen: leeftijdscategorieën, kennisterreinen, belangstellingen en levensbeschouwelijke publieksgroepen. ${ }^{3}$ Veel tijdschriften hielden het ruim en richtten zich tot 'den beschaafden stand', tot 'alle klassen van lezers' of tot 'de huisgezinnen der christenen'. Maar er waren er ook speciaal 'voor Roomsch-Catholieken', 'voor de evangelische christenheid', 'voor de Israëlieten in Nederland', 'aan het vrouwelijk geslacht toegewijd', 'voor heeren', 'voor jongens en meisjes', 'voor onze krijgslieden', 'voor aankomende onderwijzers', 'voor vrienden en beoefenaars der toonkunst', 'voor beminnaren van den schouwburg', 'voor eerstbeginnenden en gevorderden in de teekenkunst' en 'voor dames-kleêrmaaksters'. 
Veel tijdschriften formuleerden hun doelstellingen ruim - 'tot nut en vermaak', 'tot wetenschappelijk en gezellig onderhoud', 'ter verspreiding van algemeene en nuttige kundigheden' of zelfs 'tot rust en geluk der volken' - en wijdden zich aan algemene categorieën als 'wetenschappen, kunsten en letteren' of zelfs 'letterkunde, schoone kunsten en wetenschappen, koophandel, landbouw, zeevaart, staatkunde, wetgeving, enz., enz.' - kennelijk een redactie die op voorhand geen terrein wilde uitsluiten. Dit soort opsommingen was heel gebruikelijk in de titels van toenmalige periodieken en naslagwerken. De negentiende eeuw kende de verzamelterm 'cultuur' nog niet. Het is duidelijk in welke behoefte dat begrip voorzag toen het begin twintigste eeuw in zwang kwam. ${ }^{4}$

Maar periodieken konden ook al veel specifiekere doelstellingen hebben, zoals 'ter verdediging van de waarheden der Roomsch-Katholieke godsdienst', 'ter bevordering der huisselijke opvoeding', 'ter verbetering van den landbouw, veeteelt en boomkweekerij', 'toegewijd aan het zeewezen' of aan 'de leer en praktijk der christelijke tucht en kerkregeering', 'bij uitsluiting toegewijd aan de verbreiding der kennis van Oost-Indië', 'ter beoefening der Friesche geschied-, oudheid- en taalkunde' of 'voor de Hollandsche heerenkleeding en ter bevordering van nationale nijverheid'. We kennen periodieken die gewijd waren aan natuurwetenschappen, geneeskunde, gezondheidsleer, wiskunde, rechtswetenschap en notariaat, taal- en letterkunde en dialectstudie, geografie, land- en volkenkunde, godgeleerdheid, geschiedenis, toonkunst, economie, landbouw, mijnbouw en kunstnijverheid. Er waren er van protestants-christelijke, van gereformeerde, van katholieke, van joodse, van vrijzinnige en van humanistische signatuur. Er bestonden tijdschriften voor ambtenaren, fabrikanten, kwekelingen, ingenieurs en kinderen in diverse leeftijdsklassen. Speciale bladen bedienden degenen die beroepshalve of als liefhebber belang stelden in fotografie, telegrafie, posterijen, elektrotechniek, spiritisme, het schaakspel, de turnsport, handenarbeid, humor en rozencultuur.

Belachelijke opsomming, zult u wellicht denken; maar hoe leerzaam is alleen al deze enorme proliferatie en mate van specialisatie van het tijdschrift in de negentiende eeuw. Deze titels, doelgroepen, belangstellingsterreinen en kennisgebieden geven zicht op de kennis en de organisatie van de 
toenmalige samenleving. Ook mij - en ik dacht toch enigszins thuis te zijn in die periode - verrast het te zien voor welke specialisatiegebieden er toen al afzonderlijke periodieken op de markt werden gebracht: herenkleding, gynaecologie, fotografie, elektrotechniek, ambtenarij. Het is dezelfde ervaring als men opdoet bij bestudering van advertentiemateriaal in de toenmalige kranten en tijdschriften. Historici en neerlandici zijn tot nog toe grotendeels voorbij gegaan aan deze rubrieken, omdat zij in de bronnen vooral zoeken naar literaire vormen, poëticale opvattingen, recensies, politieke standpunten, ideeën en levensbeschouwing. Voor een sociale of cultuurgeschiedenis die een breder belang stelt in het dagelijks leven van mensen in het verleden, in de burger als consument, in het werkelijke gebruik van kranten en tijdschriften, valt er nog veel te halen uit advertentiemateriaal en uit een overzicht van specialisaties in periodieken. Zo begint inderdaad de persgeschiedenis zich nieuwe doelen te stellen sinds het verhaal over de politieke ontwikkeling van Nederland niet meer echt omstreden is en de verzuiling als onderwerp wel zo ongeveer is afgesloten. Voorheen stonden in her dagbladonderzoek de politieke koers en de institutionele organisatie centraal. Inmiddels beseffen pershistorici dat lezers hun krant veelal op heel andere elementen beoordelen dan op de mate waarin zij zich kunnen vinden in het hoofdredactionele commentaar. De gevarieerdheid, de advertenties, de service- en human interest-rubrieken binden de lezers minstens evenzeer als de richting van de krant. In het onderzoek naar deze functies en naar de 'journalistieke cultuur' die zich gelijktijdig met de verbreding en popularisering van de krant vormde, ligt momenteel het programma van het dagbladonderzoek. ${ }^{5}$

Zou dat niet ook moeten gelden voor het tijdschriftenonderzoek? Voor het grootste deel van de negentiende eeuw is het kunstmatig een scherp onderscheid aan te brengen tussen vorm en terrein van 'kranten' enerzijds en 'tijdschriften' anderzijds. Lang niet alle 'couranten' verschenen al dagelijks. Door de betrekkelijke traagheid van de nieuwsvoorziening konden ook wekelijkse nieuwsbladen nog met kranten concurreren. En voor een belangrijk deel vervulden week- en maandbladen nog functies die de meestal erg beknopte en gortdroge dagbladen lieten liggen, zoals duiding van het nieuws, wetenschappelijke berichtgeving, bredere beschouwing en verstrooiing. Pas 
na de opheffing van het dagbladzegel (1869) en vooral na 1880 zijn kranten zich breder gaan ontwikkelen en hebben zij steeds meer tijdschriftelementen overgenomen.

De enorme veelheid aan periodieken die er in de negentiende eeuw op de markt waren, stelt ons voor het probleem van een ordening. Welke typen tijdschriften bestonden er en hoe verhielden zij zich tot elkaar? Welke publieksgroepen bedienden zij, wat was hun functie? Veronderstelden hun verschillende niveaus, ambities en specialismen een bepaalde tijdschrifthiërarchie? Was bijvoorbeeld het academische intellectuelentijdschrift De Gids in dit landschap een erkende top of was dit maandblad temidden van diverse grotere en populairdere publieksbladen ook toen al een enigszins marginaal elitemedium? Waar bevond zich de categorie van het algemeenculturele tijdschrift?

Die vraag is al niet eenvoudig te beantwoorden, want deze benaming bestond toentertijd nog niet. Johannes past de term 'algemeen-cultureel' toe op een type achttiende- en negentiende-ecuwse periodicken. ${ }^{6}$ Sinds ongeveer 1760 probeerden tijdschriften zoals de Vaderlandsche Letteroefeningen meer te zijn dan het zeventiende-eeuwse geleerdentijdschrift, het wetenschappelijke nieuwsjournaal en de losse verzameling van letterkundige bijdragen. $Z$ ij combineerden wetenswaardigheden, verstrooiende letterkunde, duiding, boekrecensies en meningsvorming. Dat kon gebeuren op verschillende niveaus van ambitie en in allerlei verhoudingen tussen deze onderdelen. Zo waren er algemeen-culturele periodieken voor zeer gevorderde lezers en voot een breder, minder ontwikkeld publiek. Binnen deze ruime formule begon dit type tijdschriften zich al in de achttiende eeuw te diversifiëren naar specifieke doelgroepen - vrouwen, jonge lezers, gezindten, regio's of vakgebieden. De aanduiding 'algemeen-cultureel' staat hier dus voor een format, een tijdschriftrecept dat op allerlei manieren kon worden gebruikt, maar dat weinig zegt over het ambitieniveau.

Voor de categorie waartoe in Nederland een maandblad als De Gids behoorde, bestond eigenlijk geen contemporaine term. De tijdschriften die Johannes als voorbeeld nam, noemden zich Letteroefeningen, Nederlandsche Bibliotheek, Algemeen magazijn van Wetenschap, Konst en Smaak en Algemeene Konst- en Letterbode. De aanduiding 'tijdschrift' kwam in Nederland, net als in Duits- 
land, rond 1760 in gebruik en heeft zich in de negentiende eeuw doorgezet als belangrijkste soortnaam. Maar nog heel lang heeft deze aanduiding moeten concurreren met titels als 'Keur', 'Bloemlezing' of 'Verzameling', met 'Magazijn', met 'Bibliotheek', 'Museum', 'Galerij' en 'Panorama', of met 'Album' en '-boekje'. De oudere titel 'Mercurius' werd zeldzaam, maar er bleven nog heel wat '-boden'. De naamgeving van periodieken is op zichzelf een studie waard, want vaak ligt daarin een opvatting over hun aard en taak besloten. In veel van die titels komt bijvoorbeeld minder de dynamiek van de tijdsvoortgang tot uiting dan een encyclopedisch en museaal ideaal van kennisverzameling en presentatie (zoals in Magazijn, Bibliotheek, Museum, Galerij). Of de suggestie van selectie (Bloemlezing, Keur, Lettervruchten). Of de vorm van het boek-in-afleveringen, jaarlijks gebundeld in een verzamelband, zoals inderdaad vaak de praktijk was.

De regelmatig terugkerende titel 'Magazijn' had daarnaast een internationale klank. Het is waarschijnlijk de enige titel die zowel in het Engels, Frans en Duits als in het Nederlands gebruikelijk was. Dat geldt merkwaardig genoeg niet voor een andere internationaal gangbare aanduiding, 'Revue' of 'Review', die wel de Duitse vertaling 'Rundschau' heeft gekregen, maar in Nederland niet werd nagevolgd. De incidentele benamingen ' $\mathrm{Ga}$ lerij', 'Panorama' en 'Recensent' komen et misschien enigszins in de buurt. Toch is de categorie periodieken die in Frankrijk als 'Revue', in Groot-Brittannië als 'Review' of als 'Magazine' en in Duitsland als 'Rundschau' werd aangeduid ongeveer het equivalent van het Nederlandse negentiende-eeuwse tijdschrift dat we nu 'algemeen-cultureel' zouden noemen.'

Ik denk dan aan de Britse Edinburgh Review en Quarterly Review uit het begin van de negentiende eeuw (hoewel dit kwartaaluitgaven waren met louter lange refererend-recenserende overzichtsartikelen, zonder bellettrie of vrije essays), en aan de betoemde monthlies sinds de jaren 1860, zoals de Fortnightly Review, Contemporary Review en The Nineteenth Century. Het internationale model bij uitstek was de Parijse Revue des Deux Mondes (1829) onder de energieke leiding van François Buloz. Zij verscheen tweewekelijks en omvatte zowel beschouwingen als kritiek, opstellen op allerlei gebied, actuele bellettrie en overzichten van buitenlandse literatuur, actuele politiek, ontwikkelingen in de wetenschap en de stand van de academische kunst in Parijs. Hoewel het Duitse cultuurgebied sinds de achttiende eeuw kwalitatief goede tijdschrif- 
ten op deelgebieden uit dit geheel kende, duurde het tot na de eenwording van het Duitse Rijk (1871) voordat ook Duitsland zijn equivalent van de Revue des Deux Mondes kreeg in de Deutsche Rundschau (1874) van Julius Rodenberg. Inmiddels is de term 'Rundschau-Zeitschriften' ook in Duitsland gevestigd, maar tot voor kort ordenden de grote Duitse tijdschriftbibliografieën het hele tijdschriftenaanbod nog onder de verzameltermen 'Literarische Zeitschriften', 'Politische Zeitschriften' of 'Politisch-literarische Zeitschriften'.

In Nederland zou ik er, op grond van vorm, aspiraties en inhoud, periodieken zoals de Vaderlandsche Letteroefeningen, de Nederlandsche Stemmen over Godsdienst, Staat, Geschied-en Letterkunde, Het Leeskabinet, De Gids, De Tijdspiegel, de Nederlandsche Spectator, De Nieuwe Gids, het Tweemaandelijksch Tijdschrift en misschien Eigen Haard toe willen rekenen. Dat waren meest maandbladen met een zekere omvang (6o-20o bladzijden) en een breed gevarieerde inhoud, met artikelen van beoordelende, opiniërende en opinievormende aard en met min of meer de ambitie om op literair gebied 'bij de tijd' te zijn, leiding te geven en kwaliteit te bieden. Wat hun publiek en kring van medewerkers betreft richtten deze bladen zich, om een meergebruikte negentiende-eeuwse vergelijking aan te halen, niet louter tot de gasten, maar voor een deel ook tot de koks - schrijvers, wetenschapsbeoefenaren en leidinggevenden.

Waar bevond dit type blad zich nu in het toenmalige tijdschriftenaanbod? Ik doe een poging enige geledingen aan te brengen in de enorme hoeveelheid periodieken. Aan de ene kant van het spectrum stonden de tijdschriften die zich met hun gemengde formule richtten tot een breder publiek, de populaire publiekstijdschriften (wat overigens niet betekent dat zij er werkelijk in slaagden een publiek van enkele duizenden afnemers te bereiken). Men kan daarbij denken aan het Nederlandsch Magazijn ter verspreiding van algemeene en nuttige kundigheden (1834-1867), in het laatste kwart van de negentiende eeuw gevolgd door bladen als de Hollandsche illustratie (1864-1919, de Nederlandse versie van ('illustration), de Katholieke Illustratie (1867-1968), Eigen Haard (1875-1941), het Geillustreerd Weekblad voor de Huiskamer (1887-1904), de Nederlandsche Illustratie (1889-1942), de Gezellige Zondagscourant (1881) en de Geillustreerde Bladen. Tijdschrift voor iedereen (1891-1895). Dergelijke familie- en publieksbladen boden nuttige en onderhoudende wetenswaardigheden op allerlei gebied (uitvindingen, technische en land- en volkenkundige weetjes, 
historische stukjes en berichten over exotische en spectaculaire verschijnselen) - reader's digest, afgewisseld met moraliserende betoogjes, verstrooiende bladvulling en (meestal vertaalde) verhaaltjes of een romanfeuilleton. Zulke informatie bleef doorgaans ver weg van politiek, actualiteit en controversiële maatschappelijke thema's. Veel materiaal was vertaald, zoals de hele formule ontleend werd aan het Engelse voorbeeld van de Penny-Magazines of aan het Franse model van l'illustration. Het is bekend dat grote uitgevers als Kruseman, de Belinfantes en Sijthoff vaak in Nederland bladen begonnen die waren afgeleid van Engelse, Duitse en Franse succesformules. ${ }^{9}$

Evenzeer publieksgericht waren andere (meestal ook geillustreerde) bladen die een specifieker terrein van belangstelling bedienden, zoals de modebladen (Aglaja, 1848-1864, De Bazar, 1857-?, Toilet, 1876-?), de christelijke literaire leesbladen voor vrouwen en kinderen, de op actueel nieuws gerichte periodieken (het Geillustreerd Nieuws, 1866-1879, Nieuws van de Week. Lectuur voor huiskamer en keuken, 1875-1876) of De Aarde en haar Volken (1865-1940) over landen, volken en reizen.

Verwant aan dit type publieksbladen was het rijke aanbod aan bellettristische, bloemlezende tijdschriften met een opbouwend-verstrooiend karakter. Hun doel was niet de literatuur vooruit te brengen of een richting aan de literatuur te geven, maar het bieden van 'uitspannings-lectuur', vertaald werk, 'romantische verhalen' en vaak ook reisverhalen en historische lectuur.

Helemaal aan het andere uiterste van het spectrum verschenen sinds de jaren 1820-1830 de wetenschappelijke (vak-)tijdschriften. Zij waren soms de periodiek van een wetenschappelijk genootschap maar konden ook gewoon het initiatief zijn van academische geleerden, zonder binding aan een instelling. Voorop gingen tijdschriften voor vakgebieden als geneeskunde, scheikunde, natuurkunde en wiskunde. Het waren vaak jaarboekachtige periodieken die bedoeld waren voor berichtgeving over buitenlandse vorderingen op het vakgebied, als contactorgaan voor de Nederlandse vakgenoten of als publicatiemogelijkheid voor Nederlandse vakbeoefenaren. Waarschijnlijk was hun publiek heel gering en meestal functioneerden ze maar enkele jaren. ${ }^{10}$ Toch zette de formule van het (wetenschappelijke) vakblad door, want geleidelijk aan verschenen er ook tijdschriften voor theologie, recht, oudheidkunde, notariaat, filosofie, munt- en penningkunde, onderwijs, 
staathuishoudkunde en statistiek, landbouw, veeartsenijkunde, taalkunde, Indische taal, land- en volkenkunde, werktuigbouwkunde, entomologie, telegrafie en fotografie. Het wetenschappelijke vakblad, met een exclusievere of ruimere kring van gebruikers, verwierf zich in de loop van de eeuw een vaste plaats. Dat gold ook voor de vergelijkbare groep van special interestbladen, die niet per se van wetenschappelijke aard waren, maar wel serieuze vaklectuur vormden voor mensen met een zelfde hobby of belangstelling.

En ten slotte is er de categorie van de politiek-maatschappelijk gerichte tijdschriften. Er waren tal van periodieken die een bepaald aspect van maatschappelijk werk tot onderwerp hadden, dus weldadigheid, armenzorg of het gevangeniswezen. Ze waren vaak verbonden met een instelling of genootschap. Tijdschriften die beoordeling en opinievorming op politiek gebied tot doel hadden, waren waarschijnlijk zeldzaam. Er zijn er een paar geweest in de jaren 1820 , met staatsrechtelijke betogen en beoordeling van het beleid van koning Willem $1 .{ }^{11}$ Uit de jaren 1830-1840 kennen we de even radicale als efemere 'lilliputter-blaadjes', ${ }^{12}$ en van $1840-1845$ vulde de gematigd hervormingsgezinde J. de Bosch Kemper zijn De Tijdgenoot. Maar pas in 1875 verscheen een echt groot en duurzaam politiek-sociaal maandblad, het statige Vragen des Tijds, het podium van de linkse liberalen, geheel gewijd aan politiek, economie en actuele maatschappelijke vraagstukken. Het was ook pas vanaf de jaren 1870 dat de kranten systematisch aan politiek gingen doen.

Met een overzicht van de soorten periodieken is evenwel het geheel van informerende en opinievormende media in de negentiende eeuw nog niet in kaart gebracht. Van een moeilijk te overschatten belang was bijvoorbeeld de kansel: een krachtig middel om de publieke opinie te beïnvloeden, met een landelijke dekking en wekelijkse regelmaat. Dan was er het dichte netwerk van het genootschappelijk verkeer en verenigingsleven. In genootschappelijk verband hoorde het publiek eindeloos veel 'verhandelingen' aan, die vaak later ook verschenen in de tijdschriften. Er was daaromheen nog een groot circuit van populariserende lezingen, over wetenschappelijke en stichtelijke zaken. Een elementaire bron van nieuws en mededelingen vormden verder de kranten en advertentiebladen. Maar wie de kranten van voor 1870 kent, weet dat deze nog een tamelijk beperkt karakter hadden. $\mathrm{Z}_{\mathrm{ij}}$ boden 
gortdroog zakelijk en feitelijk nieuws en deden weinig aan duiding, beoordeling en opinievorming.

Misschien het meest karakteristieke, maar tot heden in het onderzoek meest onderbelicht gebleven toenmalige medium is het pamflet of de gelegenheidsbrochure, waarvan elke politieke, maatschappelijke of godsdienstige kwestie er tientallen opleverde, vaak met een lokaal bercik, soms breed verspreid. Het pamflet was een wendbaar en individueel medium. Het was enerzijds actueel als de krant, maar had anderzijds door zijn omvang - ongeveer die van een preek of verhandeling - het intellectuele gewicht van een maandbladartikel. De pamfletauteur was ongebonden en kon dus vrij opereren. Gedurende de hele negentiende eeuw heeft deze publicatievorm zich staande gehouden tussen de kranten en de week- en maandbladen. Heeft het tijdschrift inmiddels erkenning gevonden als studieobject, het pamflet is nog nauwelijks opgemerkt als niche in het pershistorisch onderzoek. Toch kan geen studie van de publieke opinie(-vorming) in de negentiende eeuw een correcte voorstelling geven zonder bestudering van deze publiciteitsvorm.

$\mathrm{Na}$ deze omtrekkende bewegingen is nog steeds de vraag welke de plaats en bedoeling zijn geweest van het algemeen-culturele of revuetijdschrift in dit medialandschap. Heel in het algemeen probeerden zij al deze elementen bijeen te houden of te brengen. Zij deden dat bovendien vanuit een missie en een opvatting over kwaliteit. Algemeen-culturele tijdschriften waren weliswaar breed en gematigd, maar zij werden doorgaans gemaakt door een redactie met een programma en droegen vaak het persoonlijk stempel van een leidende redacteur. $\mathrm{Zij}$ waren meer een redacteurs- dan een uitgeversinitiatief. Het publiek dat zij zochten was niet al op voorhand aanwezig, een herkenbare doelgroep als gegarandeerde afnemer. Door een literair, politiek of levensbeschouwelijk gemarkeerd programma organiseerden en vormden zij zich een publiek. Het is een vermogen van tijdschriften in het algemeen maar van het ambitieuze revuetijdschrift in het bijzonder dat zij een publiek ertoe brengen zichzelf te 'herkennen' als groep met een zelfde ideaal of overtuiging. ${ }^{13} \mathrm{Zij}$ zijn daarom nooit louter een 'spiegel' van hun cultuur en maatschappij, maar vormgevers. Zij scheppen formaties, articuleren menin- 
gen en creëren een openbare discussie- en informatieruimte die een ontwikkelde 'publieke opinie' eerst mogelijk maakt.

De revuetijdschriften, met hun lange beoordelende artikelen en brede overzichten, beschouwden zichzelf als een buitenschoolse en buitenkerkelijke vorm van permanent hoger onderwijs, een instituut voor hogere algemene ontwikkeling. Zij zijn wel te vergelijken met de negentiende-eeuwse universiteiten. Ook het universitair onderwijs was breed propedeutisch en encyclopedisch, niet diepgaand specialiserend. De universiteit was minder researchinstelling dan Bildungsinstituut. De verschuiving naar specialisering en zuiver wetenschappelijk onderzoek verliep langzaam, maar vond onmiskenbaar plaats. En naarmate de kennis specialistischer werd en de wetenschapsgebieden uit elkaar dreven, probeerden de revuetijdschriften een middle ground te blijven bieden, een plaats waar deskundigen uit verschillende vakgebieden elkaar en een geïnteresseerd lekenpubliek op de hoogte hielden van nicuwe ontwikkelingen. Wel verschoof met het doorzetten van de specialisatie in de natuur- en de levenswetenschappen het accent van verslaggeving over wetenschap naar beoordeling van de levensbeschouwelijke en maatschappelijke implicaties van die wetenschappelijke ontwikkelingen.

Behalve met de universiteit kan men de bedoeling van het revuetijdschrift ook vergelijken met die van het Konversationslexikon, bijvoorbeeld de Duitse Brockhaus: een lopende encyclopedie van al die dingen die men "behoort te weten' om in beschaafd gezelschap als gebildet te mogen gelden. Hier ligt een verschil tussen 'nuttige kennis' en 'beschaafde kennis'. De revuetijdschriften hadden de ambitie de smaak en het kritisch oordeelsvermogen te vormen van de bovenlaag van maatschappelijk en politiek verantwoordelijke burgers.

Vaak stelden zij zich ook een nationale taak: hun publiek op te voeden in 'nationaliteit' en de kwaliteit van de nationale cultuur te bevorderen - een belangrijk element in de erkenning van nationale zelfstandigheid en het verwerven van internationaal prestige in de negentiende eeuw. De grote revuetijdschriften - in Nederland De Gids, in het buitenland de hiervoor genoemde revues, reviews, magazines en Rundschaus - probeerden ook zelf de status te bereiken van 'het grote nationale tijdschrift', de verzamelplaats van de beste auteurs, het centrale forum voor intellectueel debat en het visitekaartje van de nationale cultuur in het buitenland. Daarom neigden zij naar een ge- 
matigd (vaak liberaal getint) standpunt. Zij wilden, bij behoud van kwaliteit en programma en in het besef dat hun kring van medewerkers en publiek nu eenmaal relatief klein was, een zo breed mogelijk podium bieden.

Zoals de revuetijdschriften een ontmoetingsplaats voor de zich specialiserende vakbeoefenaren bleven, fungeerden zij tevens als een soort vervolg op het genootschappelijk circuit. De genootschappelijke sociabiliteit vormde een 'naar binnen gerichte' openbaarheid. Hoewel er een indrukwekkend netwerk van genootschappen en verenigingen bestond, had elk van die kringen toch een zekere beslotenheid. Zij traden wel naar buiten met hun genootschapspublicaties, maar de revuetijdschriften fungeerden vervolgens als een verbredend verlengstuk. Zij brachten als het ware de genootschapscircuits in een nieuwe, echt openbare ruimte. Of zij namen zelf de vorm aan van een open genootschappelijke ruimte, waar de verhandelingen voor iedereen waren en de gewoonlijk besloten debating society op papier in het licht van de openbaarheid trad. Zo brachten deze tijdschriften, na de achttiende-eeuwse fase van de sociabiliteit, een nieuwe uitbouw van de publieke communicatie.

Wat ik hier bied, is maar een eetste schets, open voor kritiek, open voor nadere uitwerking. Ik hoop dat vele nieuwe studies in de komende jaren de culturele en maatschappelijke functie van het tijdschrift zullen verhelderen. Hopelijk zal het onderzoek noch te fundamenteel worden opgezet, zodat het niet van de grond komt, noch te zeer versnipperd en planloos worden aangepakt. Een doordacht en realistisch onderzoeksproject kan tot de benodigde resultaten leiden. Het zou eens tijd worden.

$\rightarrow$ Remieg Aerts is verbonden aan de Vakgroep Geschiedenis van de Rijksuniversiteit Groningen. Hij publiceerde onder meer De Letterheren. Liberale cultuur in de negentiende eeuw: het tijdschrift De Gids (Amsterdam 1997). 
1. Het Vaderland, 8-1-1875, 9-1-1875, 6-2-1875, $10-2-1875,10-3-1875,13-3-1875,14-5-1875$, 20-5-1875, 11-6-1875, 10-7-1875, 10-9-1875, 12-10-1875, 15-11-1875, 30-3-1876. Met dank aan drs. J.H. Furnée.

2. G.J. Johannes, De barometer van de smaak. Tijdschriften in Nederland 1770-1830, Den Haag 1995; J. Hemels en R. Vegt, Het Geillustreerde Tijdschrift in Nederland. Bibliografie, $3 \mathrm{dln}$., Amsterdam 1993-1997; C. Willems-Bierlaagh, Nederlandse vrouwentijdschriften 1800-1945, Amsterdam 1992; L. Jensen, 'Bij uitsluiting voor de vrouwelijke sekse geschikt'. Vrouwentijdschriften en journalistes in Nederland in de achttiende en negentiende ceuw, Hilversum 2001; M. Rietveld-van Wingerden, Voor de lieve kleinen. Het jeugdtijdschrift in Nederland 1757-1942, Den Haag 1992; H.A.M. Snclders, 'Natuurwetenschappelijke vaktijdschriften tond 1837 , in: De Negentiende Eeuw 12 (1988), 67-80; J. van Gessel, " Eene welkome verschijning". Muziektijdschriften in Nederland 1818-1848', in: DeNegentiende Eeliw 25 (2001), 215-232.

3. Het nu volgende overzicht is gebaseerd op de tijdschriftritels in M. Mathijsen en E. Wiskerke, 'Bibliografie literaire tijdschriften 1800-1840', in: De Negentiende Eeuw 1 (1977), $13-25,2(1978), 2-8,4(1980), 2-13,7(1983)$, 260-276; W. Visser en W. van Poottuliet, Negentiende-ecuwse literair-culturcle tijdschriften in de collectie van de Universiteitsbiblitotheek van Amsterdam, Amsterdam 1985; Hemels en Vegt, deel I; en op de titels in de Nederlandse Centrale Catalogus.

4. R. Aerts en W.E. Krul, 'Van hoge bescha- ving tot brede cultuur 1780-1940', in: P. den Boer (red.), Beschaving. Een geschiedenis van de begrippen hoofsheid, heusheid, beschaving en cultuur, Amsterdam 2001, 213-254

5. H.B.M. Wijfjes, 'Perspectief in persgeschiedenis', in: Bijdragen en mededelingen betreffende de geschiedenis der Nederlanden I 14 (1999), 223-235; H.B.M. Wijfjes en J.C.H. Blom (red.), Mediageschiedenis: kansen en perspectieven, Amsterdam 1995. Zie ook de bijdragen in het themanummer 'De stad in het nieuws' van TMG. Tijdschrift voor mediageschiedenis 4/2 (2001). 6. Johannes, 8-10, 141-151. 7. W. Haacke, 'Der Zeitschrifttypus "Revue", in: Archiv für Geschichte des Buchwesens 11 (1970), 1035-1056; K.U. Syndram, Kulturpublizistik und nationales Selbstverständnis. Untersuchungen zur Kunst- und Kulturpolitik in den Rundschauzeitschriften des deutschen Kaiserreichs (1871-1914), Berlijn 1989; J.Mason, Monthly and quarterly reviews, $1865-1914$, in: G. Boyce, J. Curran en P. Wingate (red.), Newspaper history, from the seventeenth century to the present day, Londen 1978, 281-293; M. Butler, 'Culture's medium: the role of the review' in: S. Curran (red.), The Cambridge companion to British Romanticism, Cambridge 1993, 120-147; W.E. Houghton, 'Periodical literature and the articulate classes', in: J. Shattock en M. Wolff(red.), The Victorian periodical press. Samplings and soundings, Leicester 1982, 1-28.

8. W. Haacke, Die politische Zeitschrift 1665-1965, 2 dln., Stuttgart 1968-1982; H. Pross, Literatur und Politik. Geschichte und Programme der politischliterarischen Zeitschriften im deutschen Sprachgebiet 
seit 1870, Olten en Freiburg 1963; S. Obenaus, Literarische und politische Zeitschriften 1848-1880, Stuttgart 1987.

9. Hemels en Vegt, I, 97, 107, 134, 172.

10. Snelders, $67-80$.

11. N.C.F. van Sas, 'Het politieke klimaat in Noord-Nederland tijdens de crisis van het Verenigd Koninkrijk, 1828-1830', in: Colloquium over de geschiedenis van de Belgisch-Nederlandse betrekkingen tussen 1815 en 1945, Gent 1982, 103-127; P.J.E. Bieringa, Traditic en vernieuwing in het Nederlandse politiek vocabulair, $1814-1833$. Ongepubliceerde doctoraalscriptie Rijksunivetsiteit Groningen 1986; G.J. Hooykaas, 'De politisering van de Nederlandse pers', in: De Negentiende Eeuw 15 (1991) 125-136.

12. M.J.F. Robijns, Radicalen in Nederland (18401851), Leiden 1967; J.J. Giele, De pen in aanslag. Revolutionairen rond 1848, Bussum 1968.

13. R. Aerts, De letterheren. Liberale cultuur in de negentiende ceuw: het tijdschrift De Gids, Amsterdam 1997, Inleiding; F. van Vree, 'Massapers en modernisering', in: H. Kleijer, A. Knotter en F. van Vree (red.), Tekens en teksten. Cultuur, communicatic en maatschappelijke veranderingen vanaf de late Middeleeuwen, Amsterdam 1992, 95-108. 